\title{
ASSESSMENT OF THE VERTICAL PROFILE OF SEDIMENT CONTAMINATION BY HEAVY METALS FROM THE RAMSAR ECOLOGICAL SITE "MERJA ZERGA"
}

\author{
Abdelouahed MEISSARA \\ Laboratory of Geo-Biodiversity and Natural Patrimony, \\ GEOPAC Research Center, Scientific Institute, Mohammed V University, Rabat, Morocco.

\section{Kaoutar LAGLITI} \\ Laboratory of Geo-Biodiversity and Natural Patrimony, GEOPAC Research Center, \\ Scientific Institute, Mohammed V University, Rabat, Morocco.

\section{Ahmed YAHYAOUI} \\ Laboratory of Marine Biologie, Mohammed V Agdal University - Rabat. \\ Faculty of Sciences - Rabat

\section{Mohammed FEKHAOUI} \\ Laboratory of Geo-Biodiversity and Natural Patrimony, GEOPAC Research Center, \\ Scientific Institute, Mohammed V University, Rabat, Morocco.
}

\begin{abstract}
This study allowed us to note a heterogeneous and specific distribution of contamination by metallic trace elements (chromium, lead and cadmium) of the vertical profiles made in the sediment of the Merja Zerga lagoon (Kenitra province).

Indeed, the contamination profile by these 3 elements is characterized by a significant variation with high levels, which are probably linked to road traffic on motorways, and nautical activities.
\end{abstract}

Keywords: Ramsar Site, pollution, environment, health risk, water.

Cite this Article: Abdelouahed MEISSARA, Kaoutar LAGLITI, Ahmed YAHYAOUI, Mohammed FEKHAOUI, Assessment of the Vertical Profile of Sediment Contamination by Heavy Metals from the Ramsar Ecological Site "Merja Zerga". International Journal of Civil Engineering and Technology, 11(3), 2020, pp. 41-50.

https://iaeme.com/Home/issue/IJCIET?Volume $=11 \&$ Issue $=3$ 


\section{INTRODUCTION}

The Moulay Bousselham lagoon (also called the Merja Zerga), is the only tidal zone in NorthWest Africa, characterized by the confluence of marine and continental waters, whose primary productivity is very high. Its ecological originality also resides in the dynamic that takes place between freshwater and marine water. This dynamic is at the origin of the displacement of elements dissolved in water, particles and sediments between the different sectors of the lagoon. The opening and closing of the bottleneck directly influence the ecological conditions prevailing in the Merja (Mehdaoui, et al., 2001, Mergaoui, 2003).

The Merja Zerga remains exposed to a very important human activity and therefore to the risk of pollution, in particular of agricultural origin, since more than 6000 hectares of irrigated perimeters pour their drainage water through the Nador canal and the Drader wadi (Lagliti K. et al, 2019). Man-made changes make the natural development of the lagoons less noticeable; this is why in recent years there has been a growing interest in the international scientific community for these original ecosystems. A scientific study and a deep knowledge of the functioning of the lagoons are a prerequisite for any development using their remarkable properties (Carruesco (1989); Orbi (1990), Mehdaoui (1999)).

The objective of our study is to assess the vertical profile of sediment contamination by tracing elements of chromium, lead and cadmium in the Moulay Bousselham lagoon. And to have an idea on the chronology of metallic contamination of this site. The presence or absence of these residues is therefore of great health interest in predicting any water poisoning. It is also necessary to know the concentrations making it possible to present a risk for the consumer.

\section{MATERIALS AND METHODS}

\subsection{The Study Area (fig.1)}

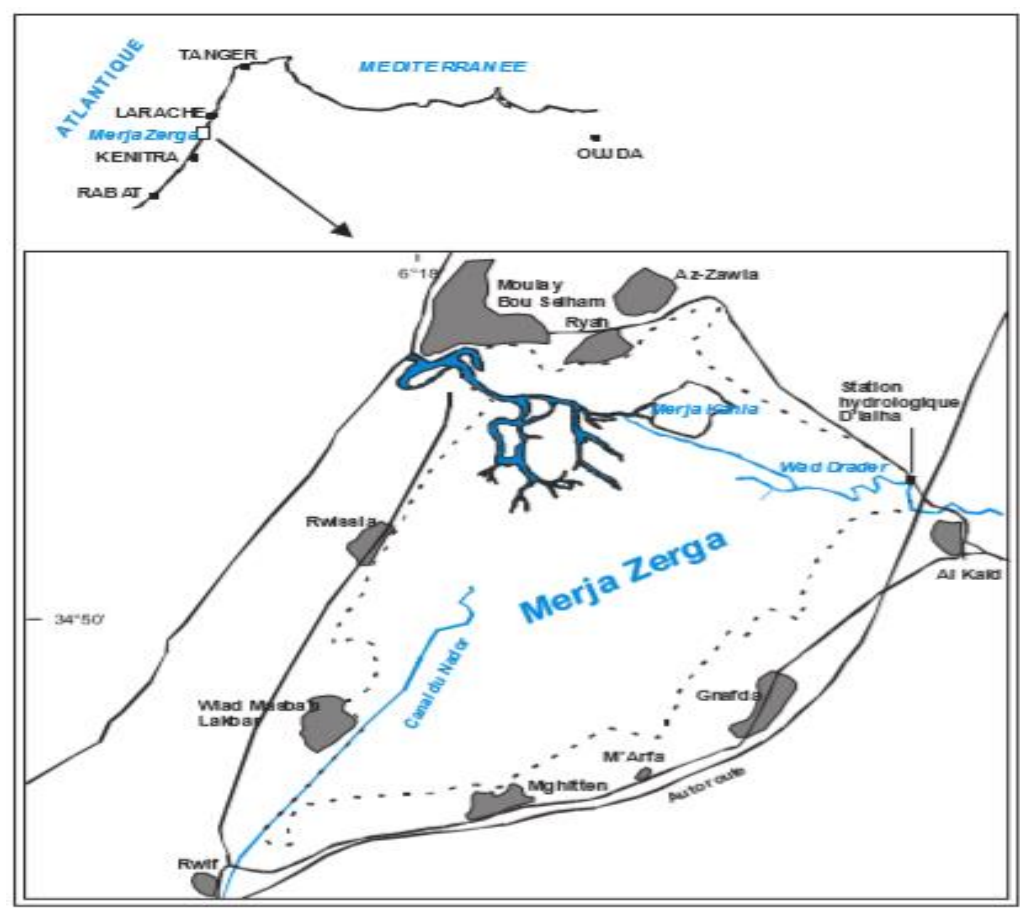

Figure 1 Location of the study area (Qninba et al., 2006)

The Moulay Bousselham lagoon is located in the northwest of central Morocco, between the Rif chain and the Meseta. It is the northernmost lagoon environment on the Moroccan 
Atlantic coast. It is located $120 \mathrm{~km}$ north of Rabat and $40 \mathrm{~km}$ south of Larache. The geographic coordinates are (P.C. BEAUBRUN- 1976) :

\section{7 and 3452 'north latitude}

613 and 614 'west longitude.

It is separated from the Sebou basin, to the south, by the hills of Lalla Zohra (100m); to the southeast by the hills of Lalla Mimouna (203m); Loukkos, to the northeast, by the hills of El Ferjane $(197 \mathrm{~m})$, Lalla Ghanno $(158 \mathrm{~m})$ and Kouricha $(143 \mathrm{~m})$. To the west, it is separated from the Atlantic Ocean by a dune cordon of gray and white sands surmounting a bed of Soltanian sandstones (Sahel).

\subsection{Hydrology (fig.2)}

The Moulay Bousselham lagoon is an elliptical depression tectonic basin, its surface is 35 $\mathrm{km} 2$, its greatest length is $9 \mathrm{~km}$ from north to south, its maximum width is $5 \mathrm{~km}$ from east to west, it communicates with the ocean by the gully leading to the pass, it is divided into two Merjas (P.C. BEAUBRUN- 1976):

- The Merja Kahla or Merja Mellah, in the North, with an area of $3 \mathrm{~km} 2$ is very shallow;

- The Merja Zerga, south of an area of $27 \mathrm{~km} 2$ with a greater depth.

At high tide, the lagoon is completely flooded, at low tide (from dead water), the Merja Mellah is completely empty of water while the Merja seems like a vast expanse of mud in which only the drainage channels remain.

Two permanent freshwater streams flow into the lagoon:

- Oued Drader which drains a small catchment area of $150 \mathrm{~km} 2$ and ends up in the lagoon in two places : The first is located at the end of the main channel, The second takes the form of a delta which interests the northeast part of the Merja Zerga upstream from the above (M. COMBE, - 1968).

- The Nador Canal transports sewage and drainage water from the areas located on the coastal fringe south of the lagoon, which constitutes more than 220,000 ha, and also forms a prograding delta (S. EL BLIDI- 2006).

The interior of the lagoon is made up of sets of water circulation channels or channels (three) whose extension is geographically variable and which presents contrasting hydrological conditions (fig. 2) ( J.C. BIDET,- 1977):

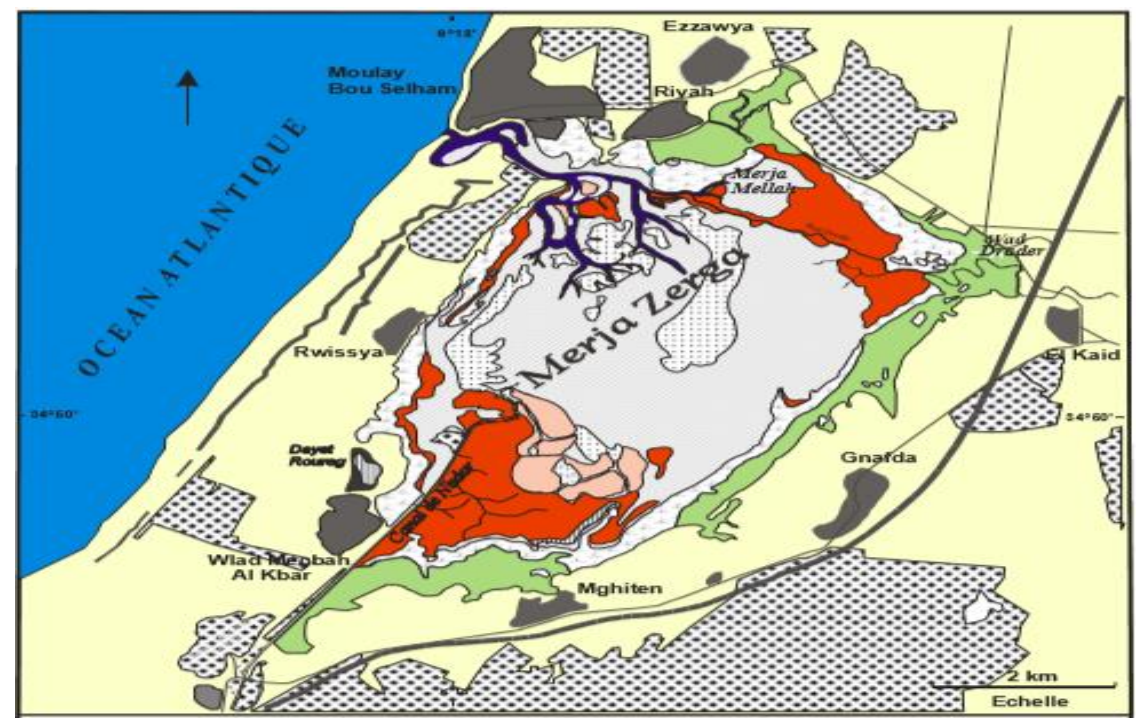

Figure 2 General presentation of the lagoon and voice of water circulation (Qninba A. et all 2006) 
- Channel I, the main straight axis with a total length of $3.8 \mathrm{~km}$, it is directly subject to the contributions of the Drader wadi and Merja Mellah.

- Channel II, the closest to the entrance but the most complex; it has several ramifications and its far end receives the drainage water from the Nador Canal. The most extreme point is $6.2 \mathrm{~km}$ from the bottleneck.

- Channel III, from a middle position; its distal end is $3.8 \mathrm{~km}$ from the pass. It is not directly subject to any of the previously mentioned effects (Benhoussa A. 2000).

\subsection{Climatology}

The region's climate is characterized by a double influence; Atlantic ocean favored at the expense of Mediterranean or continental influences (J. LECOZ, - 1964) and by a high humidity. The specific characteristics of this lagoon ecosystem are the result of the interaction of direct and indirect climatic factors. Temperature, rainfall and wind are closely related to hydrological conditions.

\subsection{Sediment Sampling Protocol}

\subsubsection{Coring area (fig.3)}

The two points (core 1 and 2) used for the core drilling operation are located inside the lagoon. The choice of these two stations was dictated by the fact that this zone is the place of mixing of the waters and transit of all the materials carried by the current taking place in the lagoon.

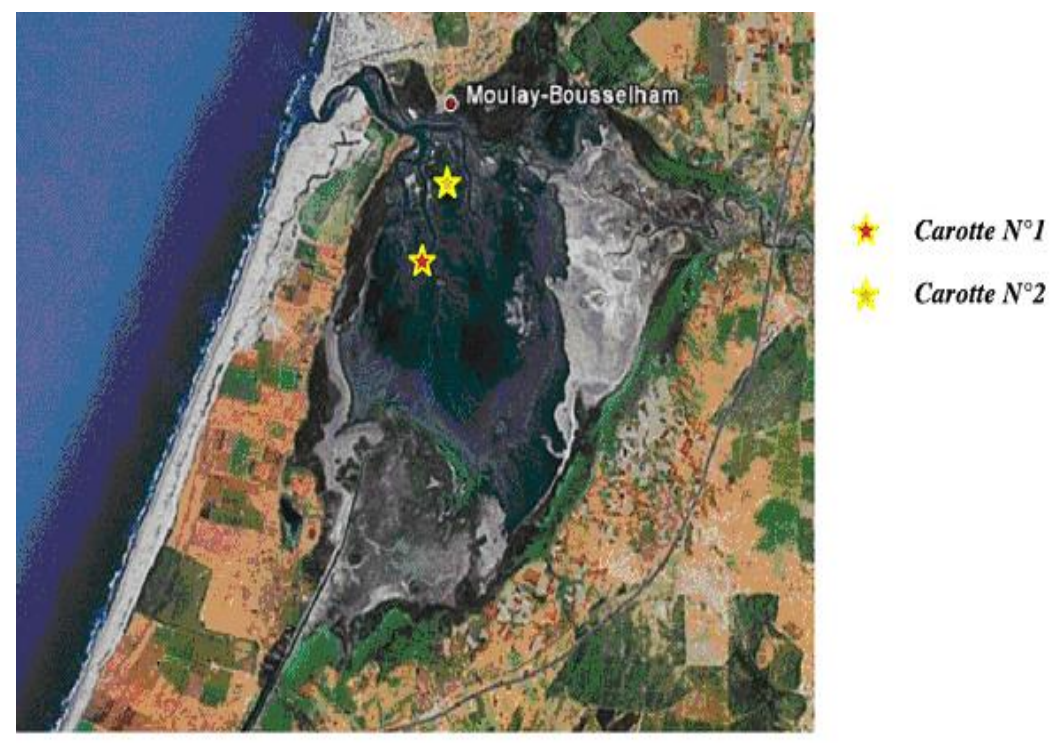

Figure 3 Location of coring points in the lagoon

\subsection{Sediment Samples}

There are many sampling methods and it is now possible to define a sampling method in accordance with the environmental conditions and the objective of the study (J.F. BEAUX L'ENVIRONNEMENT - 2004). Generally speaking, core sampling allows the structure and integrity of the surface of the sediment to be preserved and samples taken to a certain depth. For our case it is the shallow surface sediments that interested us. 
Then a local sampling of the sampled carrot was carried out, every $1 \mathrm{~cm}$ from the surface up to $10 \mathrm{~cm}$ and then every $2 \mathrm{~cm}$ to the base, after we proceeded to the conditioning (bagging and freezing) of the samples after weighing.

\subsection{Preparation of Samples}

\subsubsection{Preparation of the Materiel}

All the material used for our preparation and analysis of the samples is made of low density polyethylene (LDPE) and not glass, because lead tends to absorb on silica and not on polyethylene, polypropylene and Teflon.

The equipment was washed according to the method recommended by international organizations UNEP / FAO / COI / IAEA (1995).

The dishes are put in the presence of a liquid laboratory detergent overnight cold. Then rinse with tap water and distilled water. These dishes are then immersed in a bath of $10 \%$ nitric acid for a week in the cold and then rinsed 3 times with distilled water and 2 times with double distilled water (LAGLITI K. et al - 2019).

\subsubsection{Treatment of samples for sediment}

The samples to be analyzed are thawed and homogenized, then they are dried at $105 \mathrm{C}$ for 24 hours.

\section{Mineralization}

Weigh $0.2 \mathrm{~g}$ of sediment in $30 \mathrm{ml}$ Teflon digestion bombs we add $1 \mathrm{ml}$ of the mixture (hydrochloric acid - nitric acid) (3/1, V / V) the acid feast water and $6 \mathrm{ml}$ of hydrofluoric acid, we close the bombs and they are kept at room temperature for 24 hours for a predigestion then they are heated to $120 \mathrm{C}$ for 4 hours in a thermostat sand bath.

After cooling, make up to $50 \mathrm{ml}$ with double-distilled water in dilution tubes containing $2.7 \mathrm{~g}$ of boric acid.

\subsubsection{Analysis Method}

We chose the Varian AA20 atomic absorption spectrophotometry as an analysis method, fitted with a graphite furnace. It's a very fast method. It should be noted that for each series of analysis 3 successive readings are carried out for each solution to be measured, the average of these 3 readings to constitute the measurement. A calibration curve has been established and a blank consisting of the acids used for the attack and of the filter for the case of samples of atmospheres and prepared.

To eliminate any interference that may exist. We used background correction and a matrix modifier consisting of a mixture of $0.8 \mathrm{ml}$ of $0.2 \%$ palladium nitrate and $0.2 \mathrm{ml}$ of $1 \%$ magnesium nitrate (K. BELLAMINE, - 2006).

\section{RESULTS AND DISCUSSION}

\subsection{Metallic Trace Elements in Sediments}

The results of the analyzes carried out on all of the cores are shown in Figures 4 to 9. 


\subsubsection{Diagram of vertical contamination by chromium}

\section{Core 1 :}

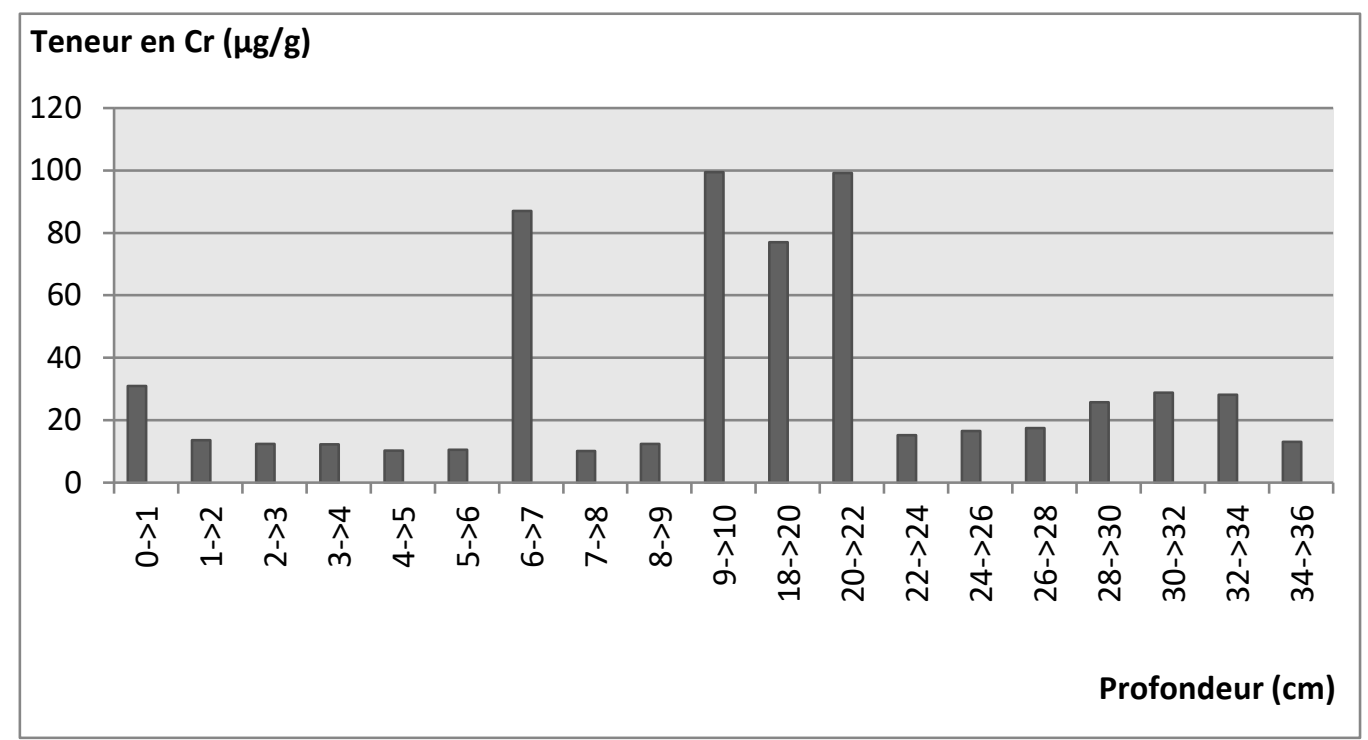

Figure 4 Diagram of contamination of core 1 by $\mathrm{Cr}$

For chromium, the contamination profile as a function of depth is characterized by a significant variation. Indeed, the layers which present the most important contents are located between depths 6-7 and 20-22 where we noted values of the order of 87, 99.4, 77 and 99.2 respectively. The early chromium is high because the rain was very abundant this year since the year was rainy the early chromium is very high the early chromium depends on the amount of rain.

\section{Core 2 :}

Teneur en $\mathrm{Cr} \mu \mathrm{g} / \mathrm{g}$ )

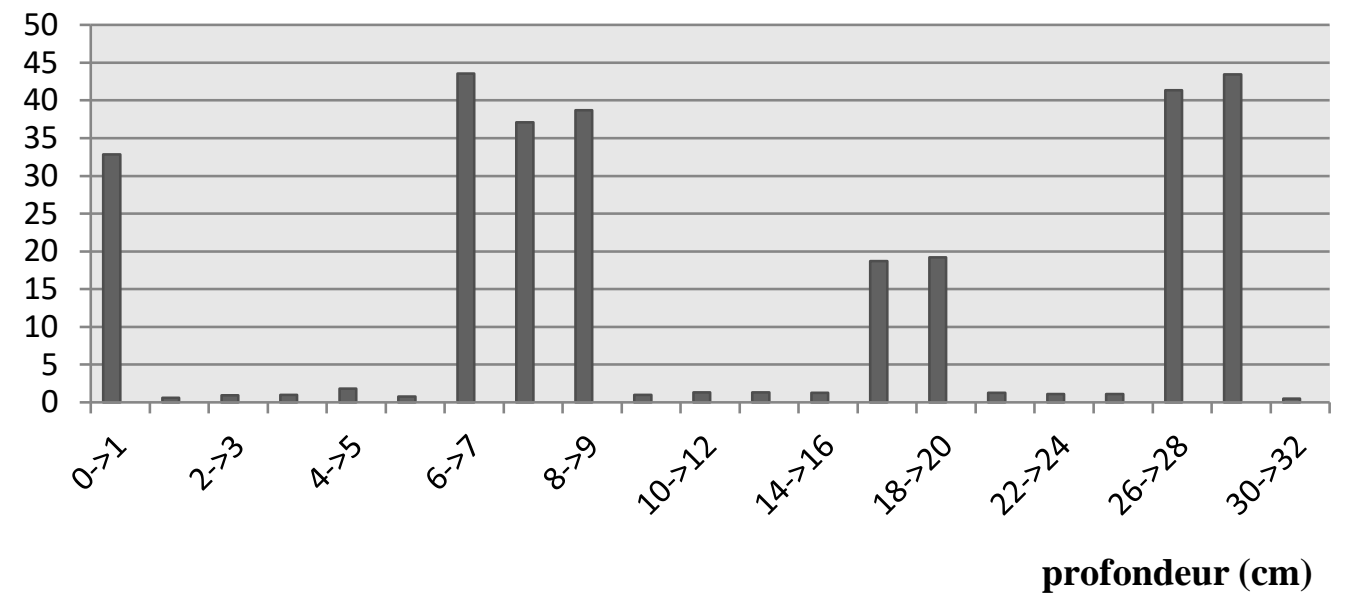

Figure 5 Diagram of contamination of core 2 by $\mathrm{Cr}$

For core 2, the large chromium values were recorded at three levels level 0-1 cm, level 6-9 $\mathrm{cm}$ and level 28-30 $\mathrm{cm}$ where we noted 33, 44, 37, 39, 41 and 43, $5 \mathrm{ppm}$ respectively.

For the rest, the variations are less significant, the maximum recorded is around $1.8 \mathrm{ppm}$ $(4-5 \mathrm{~cm})$. 
This heterogeneous distribution of the chromium content could be linked to the nature of the substrate, particularly the particle size. Indeed, according to the configuration of core $\mathrm{n} 2$ the sedimentary structure is not homogeneous. The finer the substrate (rich in organic matter, the higher the contents).

Furthermore, the origin of chromium in the lagoon is to be linked to freshwater supplies, particularly those from the rice fields which are irrigated by the waters of Sebou rich in chromium (S. EL BLIDI, M. - 2006).

\subsubsection{Diagram of vertical lead contamination}

\section{Core 1 :}

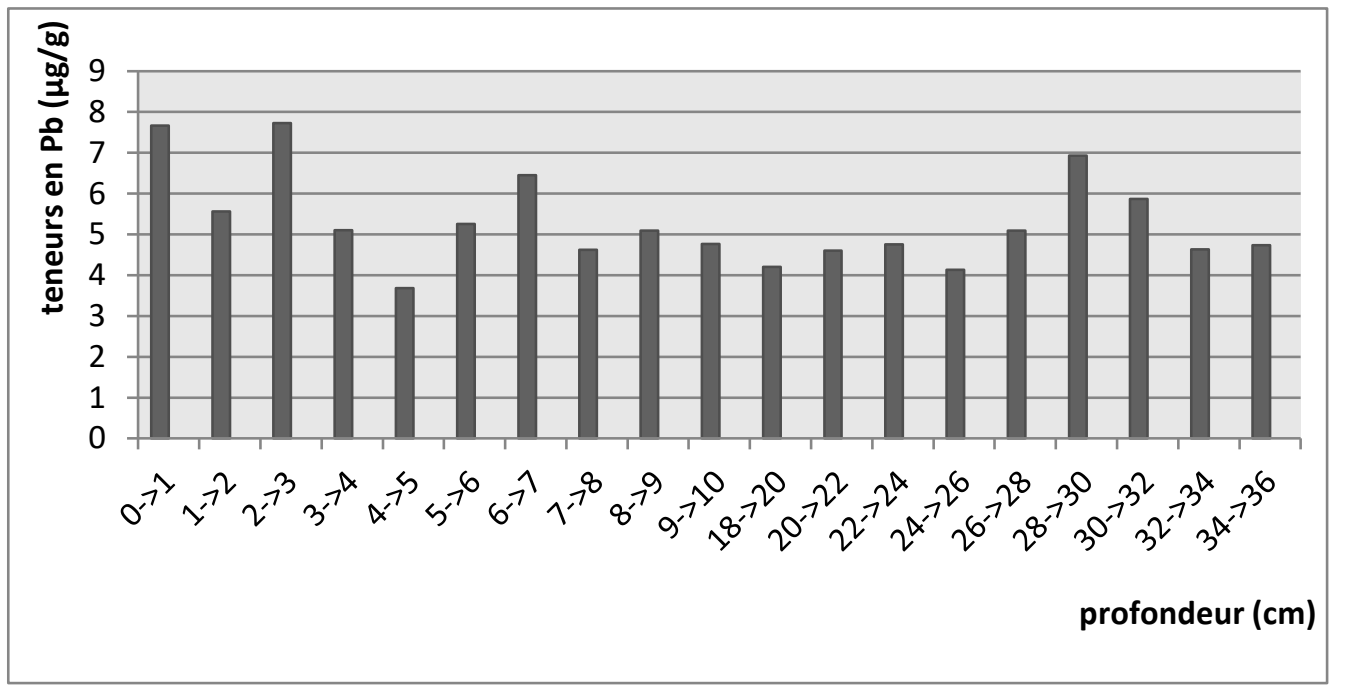

Figure 6 Diagram of contamination of core 1 by $\mathrm{Pb}$

Overall there is a general distribution of $\mathrm{Pb}$ in the vertical profile. The values are relatively large with a maximum recorded at the level of the first centimeters $(0 \rightarrow 1,2 \rightarrow 3)$ with a value of $7.5 \mu \mathrm{g} / \mathrm{g}$, while in the other depths the distribution remains almost balanced and varies between $(3,5 \mu \mathrm{g} / \mathrm{g}, 5,5 \mu \mathrm{g} / \mathrm{g})$.

\section{Core 2 :}

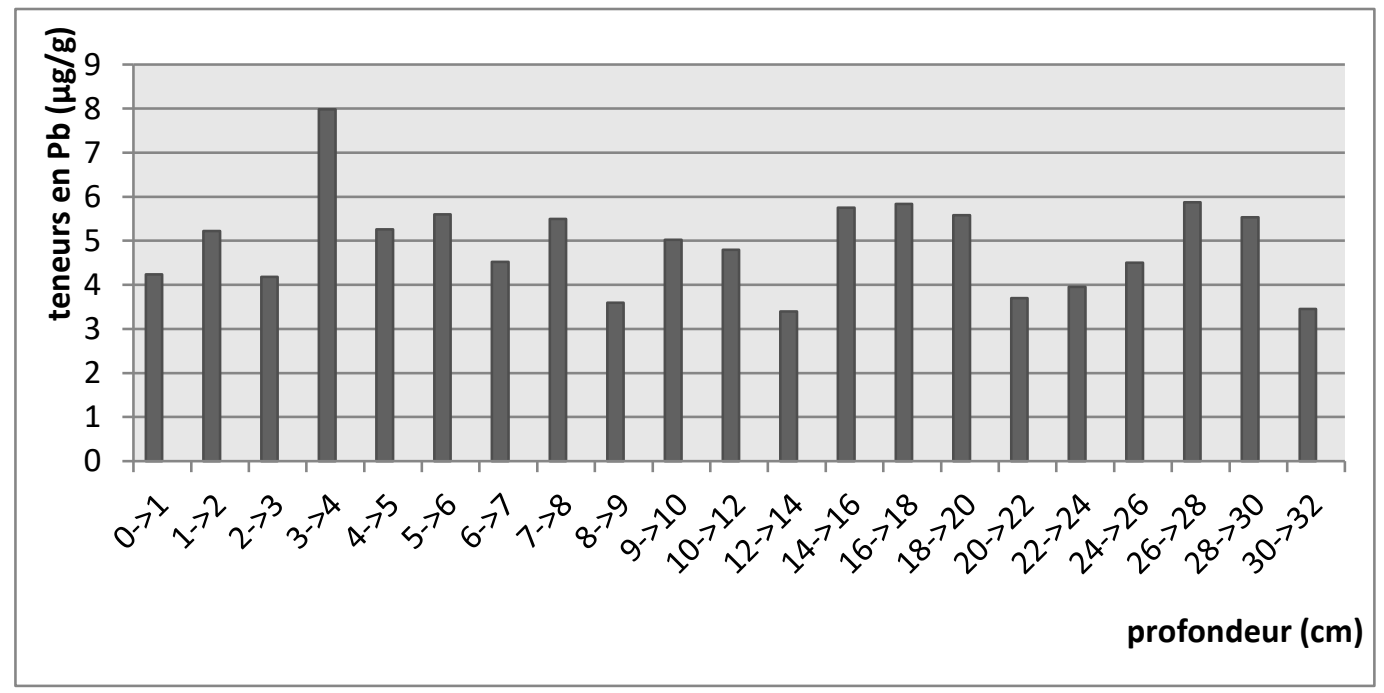

Figure 7 Diagram of core 2 contamination by $\mathrm{Pb}$ 
For this Carrot the most important value was recorded at depth 3-4 with a value of $8 \mu \mathrm{g} / \mathrm{g}$, while in the other depths the distribution remains almost balanced and varies between $3.4 \mu \mathrm{g} / \mathrm{g}$ and $5.9 \mu \mathrm{g} / \mathrm{g})$.

In the absence of any industrial activity using $\mathrm{Pb}$, this presence of lead in the sediment remains linked to the nautical activities of motor boats, to road traffic (highway).

\subsubsection{Diagram of Vertical Cadmium Contamination}

\section{Core 1 :}

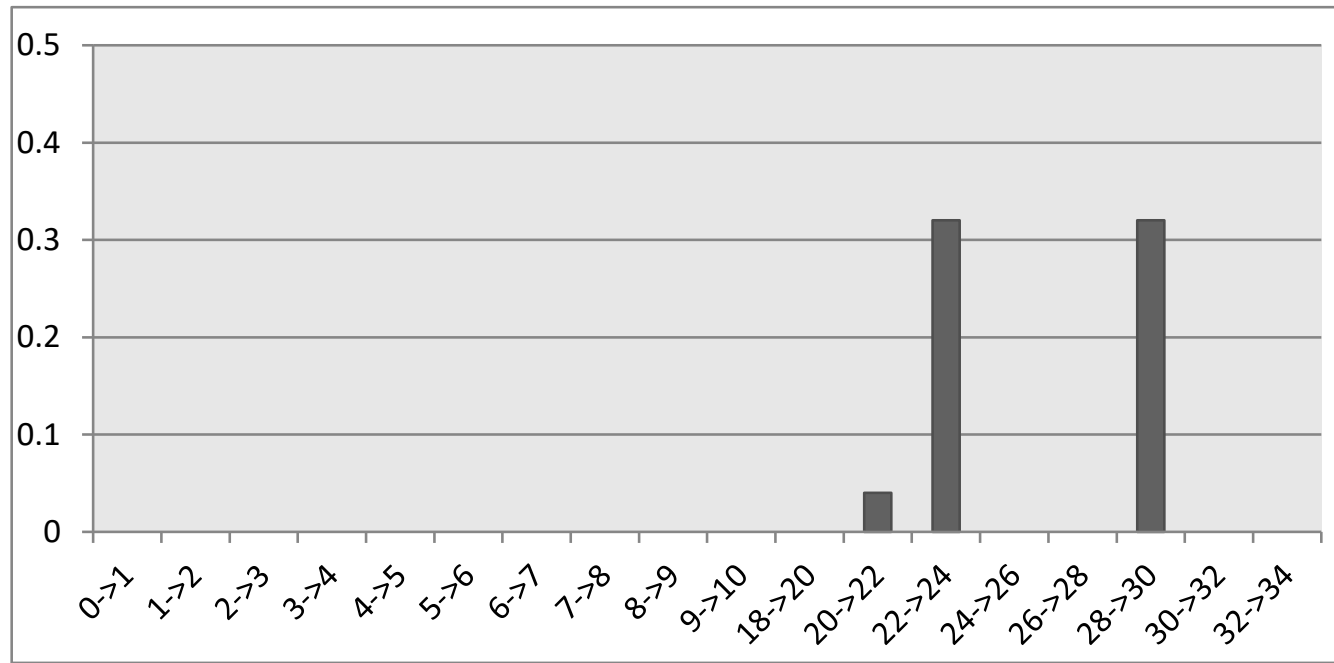

Figure 8 Diagram of contamination of core 1 by $\mathrm{Cd}$

With the exception of two readings at the level of layers 22-24 and 28-30 where values of $0.32 \mu \mathrm{g} / \mathrm{g}$ were noted for the rest there is no contamination by cadmium at the level of the surface layers.

Core 2 :

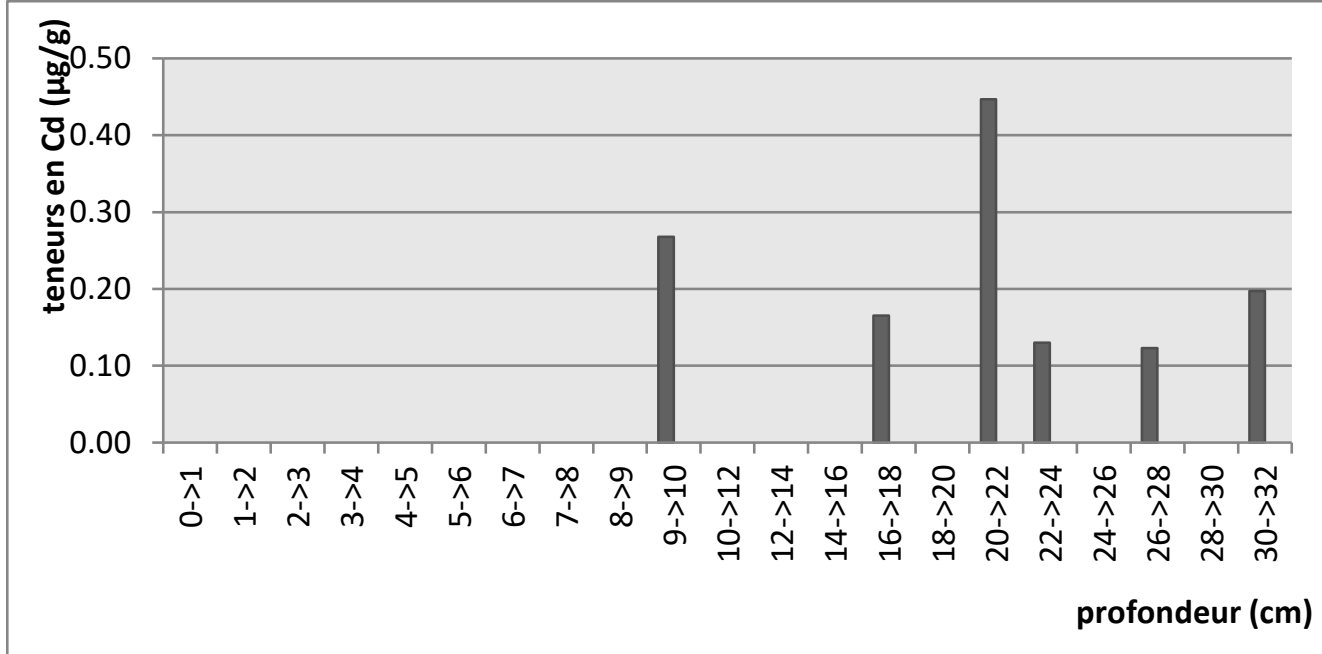

Figure 9 Diagram of contamination of core 2 by $\mathrm{Cd}$

The same remark applies for the second core where the main observation is the absence of any contamination of the surface layers. On the other hand at the level of the deep layers the values recorded at this level are not negligible and testify to a certain old contamination. 


\section{CONCLUSION}

The study of the contamination by trace elements chromium, lead and cadmium of the vertical profiles carried out in the lagoon of Merja zerga made it possible to note a heterogeneous and specific distribution.

Indeed, for chromium, the contamination profile as a function of depth is characterized by a significant variation with high contents at the level of the layers located between depths 6-7 and 20-22. In the center of the lagoon, however, the contamination is rather superficial.

For Lead, the distribution is general and homogeneous in the two points of the lagoon with relatively large values probably linked to road traffic on motorways and nautical activities.

For cadmium and according to the results obtained, the absence of contamination in the surface layers characterizes this distribution and suggests an old contamination of the lagoon.

Thus the global distribution of trace elements in the lagoon seems to be conditioned by two important factors:

1-The particle size and the sedimentary structure (M. BAYED, et al- 1998) and (C. CARRUESCO, - 1989);

2-The hydrodynamics of Merja which is very active at this level (M. BAYED, et al- 1998).

\section{REFERENCES}

[1] A. Benhoussa, 2000 - Caractérisation des habitats et micro distribution de l'avifaune de la zone humide de Merja Zerga (Maroc). Doctorat d'Etat. Dac. Sci., Rabat.

[2] C. Carruesco, - genèse et évolution de trois lagunes du littoral atlantique depuis 1'holocéne: oualidia, Moulay Bousselham (Maroc) et arcacon (France). Thése doctorat d'état, Université de Bordeaux I, tommes 1et 2, 485p, 1989a.

[3] J. Lecoz, - Le Rharb, Fellahs et Colons. Tome 1: les cadres de la nature et de l'histoire. Thèse de Doctorat, Rabat, 481p, 1964.

[4] J.C. Bidet, C. Carruesco, \& W. Gensous, - un milieu sédimentaire actuel: la lagune de Moulay Bousselham (cote atlantique marocaine). Bull. inst. Géol. Bassin d'Aquitaine, Bordeaux, n 22, 230p, 1977.

[5] J.F. Beaux -L'environnement. Repères Pratiques 160p, 2004.

[6] K. Bellamine, - étude de la contamination de la nappe souterraine de la province de kénitra le long de l'axe oulad slama-souk tlet par les pesticides organochlorés, mémoire de fin d'étude, faculté des sciences ibn tofail kénitra. 83p, 2006.

[7] Lagliti K. 2019 - Impact of agricultural products on a Ramsar ecological site 'Merja Zerga': the case of the quality of the two water emissaries Oued Drader and Canal Nador. International Journal of Civil Engineering and Technology 10(8), 2019, pp. 73-89.

[8] Mehdaoui O., Fekhaoui M., Descoins C. 2000 - Accumulation et biomagnification des insecticides organochlorés dans les mollusques et les poissons de la lagune de Moulay Bousselham, au Maroc. Inst.Sant .Dev. Cahiersd 'études et de recherche francophones/Santé.Volume 10, n 6,373-9.

[9] Mehdaoui O., Venant A., Fekhaoui M. 2000 - Contamination par les pesticides organochlorés et les nitrates de la lagune de Moulay Bousselham, Maroc Inst.Sant. Dev.Cahiers d 'études et de recherche francophones/Santé. Volume 10, n 6,381-8.

[10] Mehdaoui O. 1999 - La lagune de moulay Bouselham resere biologique e la côte atlantique marocaine: qualité chimique des eaux, contamination des différentes 
Assessment of the Vertical Profile of Sediment Contamination by Heavy Metals from the Ramsar Ecological Site "Merja Zerga"

composantes de l'écosystème par les orgnochlorés.. Doctorat de l'université, Université Parie 6, 167p.

[11] Mergaoui L. 2003-Diagnostic d'un état de pollution organique et métallique de deux zones humides: cas de Merja zerga et le bas Sebou. Doctorat National, fac Sci., Djar Mehaz, Fès, 132p.

[12] M. COMBE, - Ressources en eau du bassin Drader-Souier et principes de leur mobilisation. Ministère des Travaux Publics et des Communications. Rapport de 25p, 1968.

[13] M. Bayed, H. Bazairi, A. Benhoussa, M. Dakki, M. A. El Agbani, M. Fekhaoui, \& A. Qninba, - Diagnostic écologique de Merja Zerga: bathymétrie, hydrologie, qualité des eaux, sédiments et macrofaune benthique. Rapport inédit. AEFCS/MedWet2: Conservation et Utilisation Rationnelle des Zones Humides Méditerranéennes. 75p, 1998.

[14] Orbi A., 1990- Etude hydrodynamique de la lagune de Moulay Bousselham. Trav. Doc. N 70, INRH, Casablanca, 50p.

[15] Qninba A., Benhoussa A., El Agbani M.A., Dakki M., Thevenot M. 2006 - Etude phénologique et variabilité interannuelle d'abondance des charadriidés das un site Ramsar du Maroc : la Merja Zerga

[16] OMS, Directives de qualité pour l'eau de boisson, Deuxième édition, Additif au Volume 1, ISBN 924254514 7, Recommandations, 1998.

[17] P.C. Beaubrun - la lagune de moulay bousselham. Etude hydrodynamique et sédimentologique. Bull. inst. Sci. Rabat n 1, 22p, 1976.

[18] R. Bremond et C. Perrodon - Paramètres de la qualité des eaux. Ministère de l'environnement et cadre de vie, France.2ème édition. 259p, 1979.

[19] S. El Blidi, M. Fekhaoui, A. El Abidi, L. Idrissi, \& T. Benazzou, T. - contamination des rizières de la plaine du Gharb (Maroc) par les métaux lourds. Vecteur environnement, vol., 39, n 1, 53p. 2006. 